\title{
Measurement of field-hydraulic soil properties using suction infiltrometer for soil-based pavement
}

\author{
T. Sugii ${ }^{1}, H$. Yokawa ${ }^{1}$ and M. Ishii ${ }^{2}$ \\ i) Department of Civil Engineering, Chubu University, 1200, Matsumoto-cho, Kasugai, Aichi, Japan. \\ ii) Meiho Engineering, Inc., 6-21, Hukiage-cho, Gifu, Japan.
}

\begin{abstract}
The permeability test for permeable asphalt pavement cannot be applied to soil-based pavement in the field because this test erodes the ground surface due to the high positive applied pressure. Furthermore, the permeability test is based on the time required for a certain amount of water seepage to occur, which is not a hydraulic conductivity parameter that has a physical meaning. Therefore, in the present paper, we propose a measurement technique for water permeability and soil-water retentivity by field measurements using a suction infiltrometer. The results revealed that, even if the pavement layer is $10 \mathrm{~cm}$ in thickness, the proposed method can determine the field-saturated hydraulic conductivity. Furthermore, we determined the soil-water characteristic curve for soil-based pavement using the simultaneously measured water entry value.
\end{abstract}

Keywords: field saturated hydraulic conductivity, soil water characteristic curve, water entry value

\section{INTRODUCTION}

Recently, soil-based pavement has been used in Japan to mitigate the heat island effect and internal inundation. However, there is no in situ test method to evaluate the soil hydraulic soil properties before and after construction. Therefore, the present paper proposes a method for evaluating the field-saturated hydraulic conductivity and the soil-water characteristic curve for in situ soil-based pavement. Downward infiltration due to gravity and a suction gradient occur when water infiltrates the pavement surface [Wooding (1968) and Philip (1968)]. Reynolds and Elrick (1991) proposed that the hydraulic conductivity be determined when the water flow becomes steady. In the present study, we used the method of Reynolds and Elrick (1991) in order to determine the hydraulic conductivity of soil-based pavement.

\section{DETERMINATION OF FIELD-SATURATED HYDRAULIC CONDUCTIVITY BY SUCTION INFILTRATION GENERAL SPECIFICATIONS}

\subsection{Field-saturated hydraulic conductivity of soil-based pavement}

Soil-based pavement is formed by changing soil to an aggregated structure and improving its permeability. Micro pores in this type of pavement retain moisture and reduce the evaporation rate. Soil-based pavement has been used in several primary schools in Japan. Although there is a field permeability test for drainage in asphalt pavement, this test cannot determine the hydraulic conductivity. The field permeability test measures the time required for a certain amount of water to seep into the pavement. However, this method applies a high hydrostatic pressure (approximately 6 $\mathrm{kPa}$ ) to the pavement surface, which will cause erosion of soil-based pavement. In contrast, the suction infiltration method applies negative pressure to the soil surface, so that erosion does not occur. Therefore, the suction infiltration method was used in the present study. The thickness of the soil-based pavement was approximately $10 \mathrm{~cm}$. The applicability of this method was verified using numerical analysis.

\subsection{Measurement principle}

The rate of infiltration from a water supply disk is given as follows based on Wooding's experimental results [Wooding (1968)]:

$$
Q=\pi R^{2} k_{w u}(h)+4 R \phi(h)
$$

where $Q$ is the steady flow rate $\left[\mathrm{cm}^{3} / \mathrm{s}\right], R$ is the radius of the water supply disk [cm], $\phi(h)$ is the matric flux potential $\left[\mathrm{cm}^{2} / \mathrm{s}\right], k_{w u}(h)$ is the unsaturated hydraulic conductivity $[\mathrm{cm} / \mathrm{s}], k_{f s}$ is the field-saturated hydraulic conductivity $[\mathrm{cm} / \mathrm{s}]$, and $h$ is the infiltration head $[\mathrm{cm}]$.

The first term in Eq. (1) indicates the downward infiltration due to gravity, and the second term indicates the matric suction. If the hydraulic conductivity of unsaturated soil is defined as follows:

$$
k_{w u}(h)=k_{f s} \cdot \exp (a h)
$$

then the matric potential can be written as: 


$$
\phi(h)=\int k_{w u}(h) d h=\int k_{f s} \cdot \exp (a h) d h=\frac{k_{f s} \cdot \exp (a h)}{a}
$$

By substituting Eq. (3) into Eq. (1), we obtain the following:

$$
\therefore \log _{e}\left(\frac{Q}{t}\right)=a h+\log _{e}\left\{\left(\pi R^{2}+\frac{4 R}{a}\right) \cdot k_{f s}\right\}
$$

where

$$
\therefore k_{f s}=\frac{\exp \left\{\log _{e}(Q / t)\right\}}{\pi R^{2}+\frac{4 R}{a}}
$$

In order to determine the field-saturated hydraulic conductivity, the parameter $a$ in Eq. (5) must be known. This can be experimentally determined from the intercept of a plot of $\log _{\mathrm{e}}(Q / t)$ against the negative pressure $h$ [Nishimura (2017)], as shown in Fig. 1. The field-saturated hydraulic conductivity $k_{f s}$ when $h$ is zero can then be evaluated using Eq. (5).

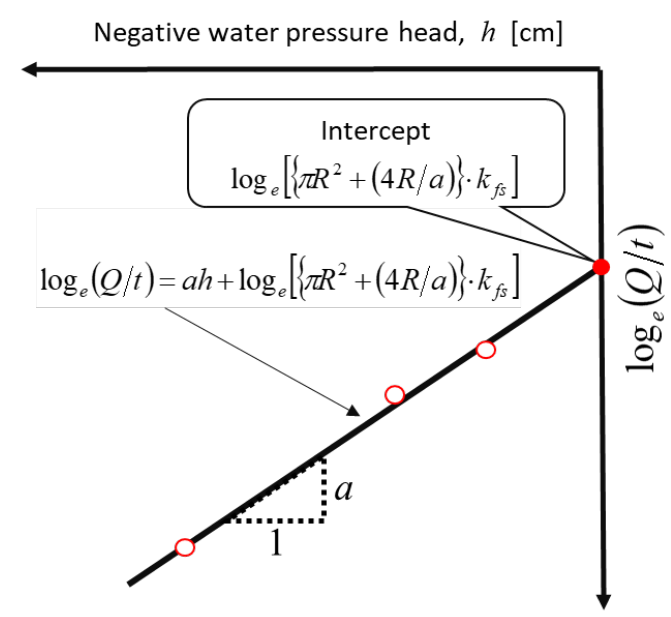

Fig.1 Gradient and intercept of Eq.(4)

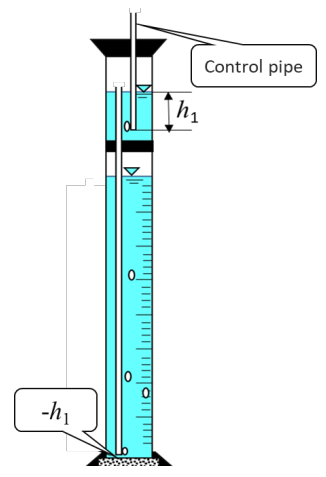

Fig.2 Minidisc infiltrometer (METER Group, Inc.)

\subsection{Experimental setup}

The suction infiltrometer comprised a water supply and a Marriott tank. In the present study, a commercial suction infiltrometer (METER Group, Inc.) was used, as illustrated in Fig. 2. It has a sintered water supply disk with a radius of $22.5 \mathrm{~mm}$. The term $h_{1}$ indicates the infiltrating pressure head of the water supply, and the pressure can be controlled by vertically moving the control pipe.

\subsection{Field-saturated hydraulic conductivity}

(1) Experimental results

The amount of infiltration was measured under three different negative pressure heads $(-4,-2$, and -1 $\mathrm{cm}$ ), and the amount of infiltration per unit time was calculated. Fig.3 is plotted of $Q$ against time. We judged an infiltration as saturated flow state when infiltration rate became constant. The field-saturated hydraulic conductivity $k_{f s}$ is determined from the intercept and gradient in Eq. (4), and the results are shown in Fig. 4. It can be seen that $k_{f s}$ of pavement (Point C) becomes higher than non-pavement (Point D). (2) Relationship between pavement thickness and radius of water supply disk

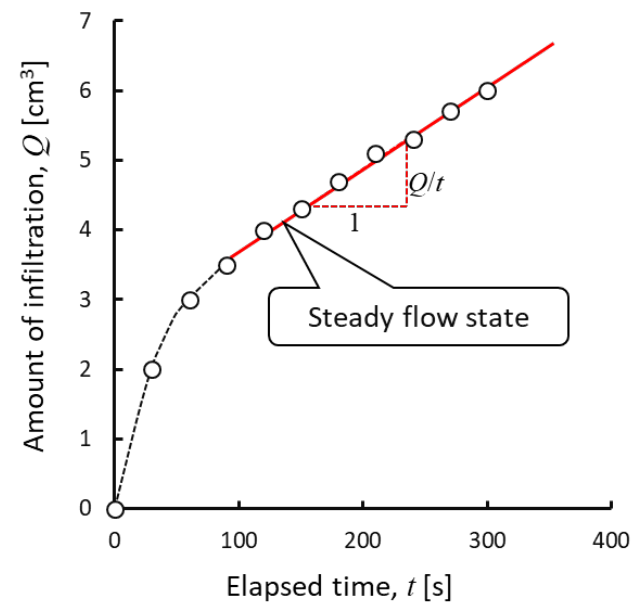

Fig.3 Change of Amount of infiltration.

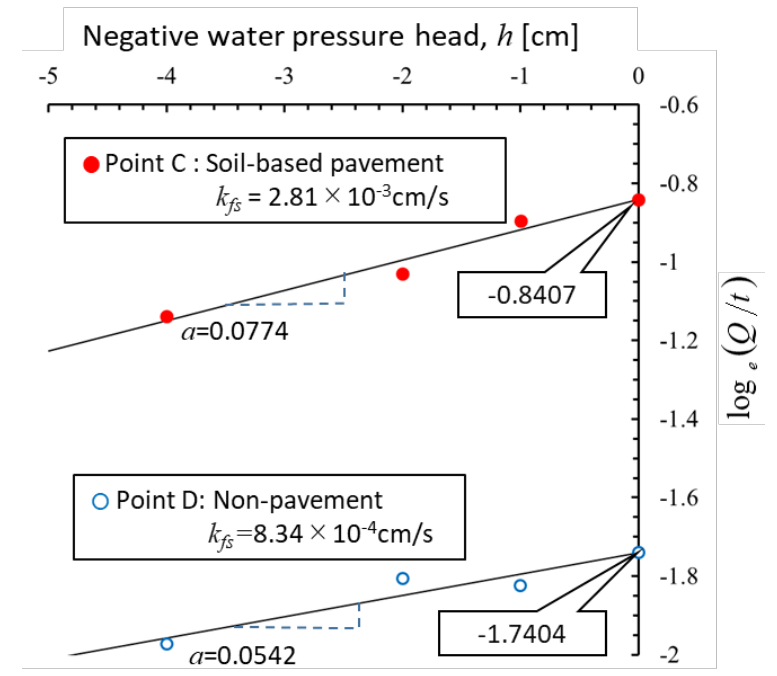

Fig.4 Experimental results.

The soil-based pavement was only about $10 \mathrm{~cm}$ thick, and in order to verify whether the measurements were finished before the infiltration depth (infiltration front) exceeds the thickness of the layer, we observed 


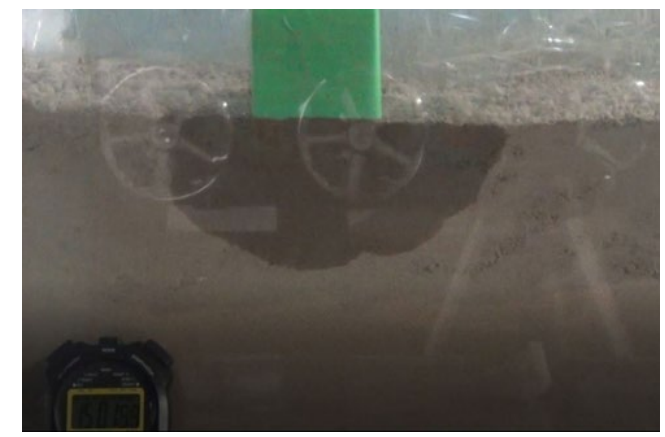

Photo.1 Infiltration front.

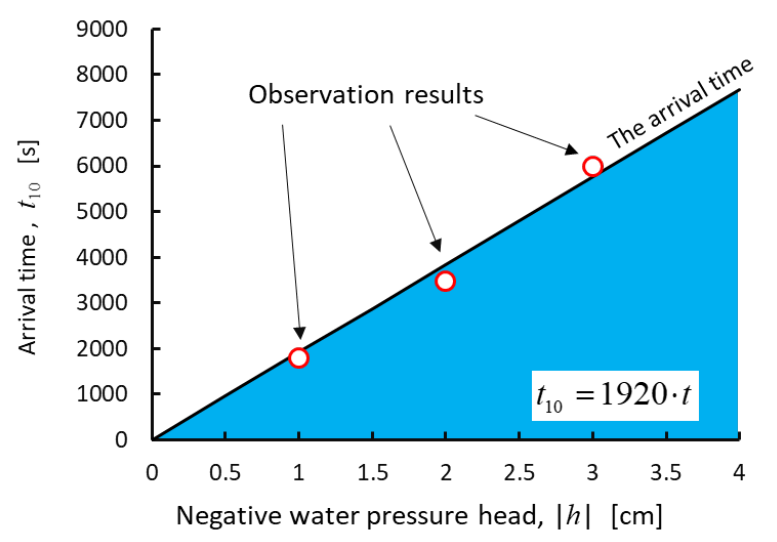

Fig.5 The arrival time of infiltration front to the top of the layer under $10 \mathrm{~cm}$.

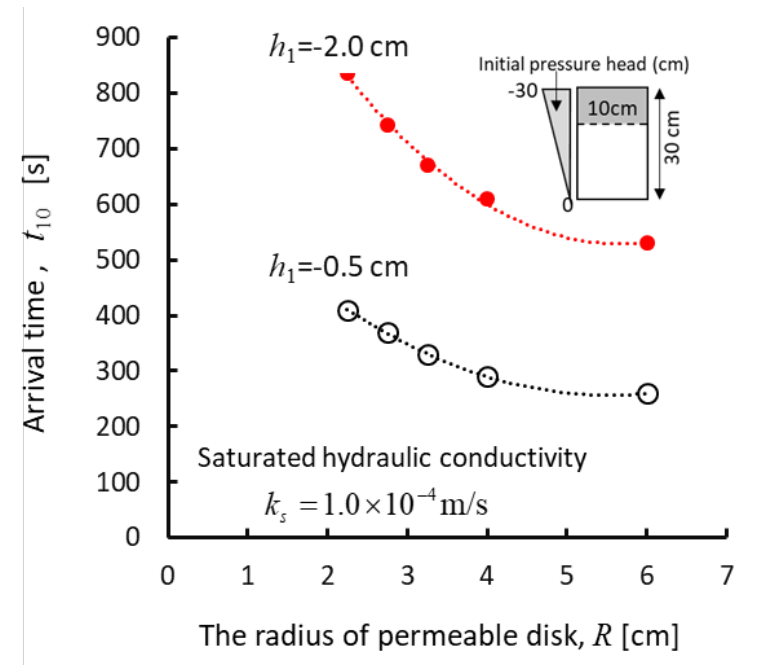

Fig.6 Influence of disk radius on the arrival time.

the infiltration process using a half-section model with the same structure as the suction infiltrometer. Photograph 1 shows the infiltration process using the the infiltration process using a half-section model with the same structure as the suction infiltrometer. Photograph 1 shows the infiltration process using the half-section model. Figure 5 shows the time of arrival of the infiltration front at a depth of $10 \mathrm{~cm}$ for negative pressure heads of $-3,-2$, and $-1 \mathrm{~cm}$. The results show that the measurements were finished before the arrival of the infiltration front at a depth of $10 \mathrm{~cm}$. To confirm this, the arrival time was numerically calculated using the software package Hydrus 2D. Figure 6 shows the dependence of the arrival time on the radius of the water supply disk for pressure heads of -0.5 and $-2 \mathrm{~cm}$. Based on the results, the greater the radius of the water supply disk, the shorter the arrival time of the infiltration.

\section{PREDICTION OF SOIL-WATER CHARACTERISTIC CURVE FOR SUCTION INFILTRATION METHOD}

\subsection{Determination of water entry value}

(1) Relationship between negative pressure supply and amount of infiltration

As previously noted, the amount of infiltration was measured for three negative pressure heads using the suction infiltration method. The relationship between the negative pressure supply and the amount of infiltration was analyzed after steady flow has occurred. Therefore, the negative pressure supply can be obtained when the velocity of the steady flow becomes zero, i.e., from the $\mathrm{x}$-axis intercept of the graph in Fig. 7.

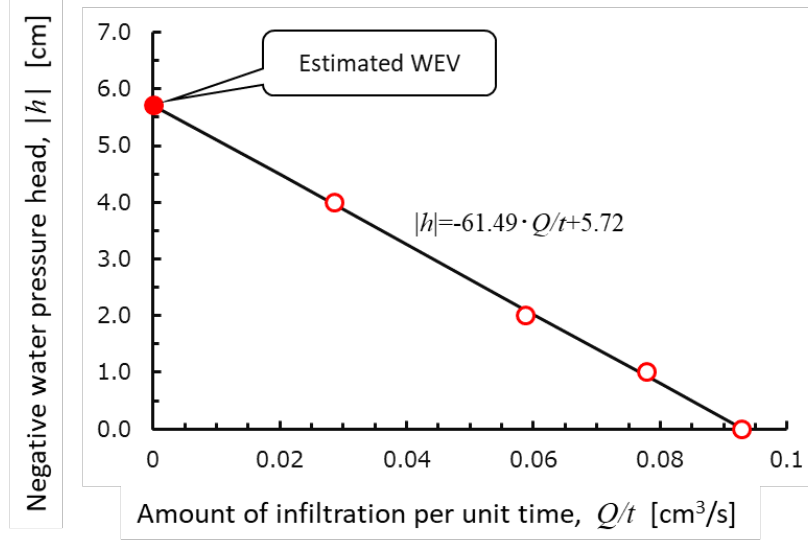

Fig.7 Prediction of $W E V$.

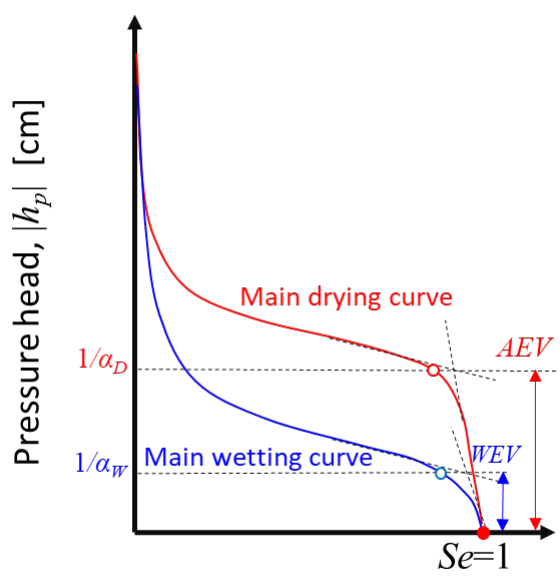

Effective saturation, $\mathrm{Se}$

Fig. $8 W E V$ and $A E V$ of $S W C C$. 


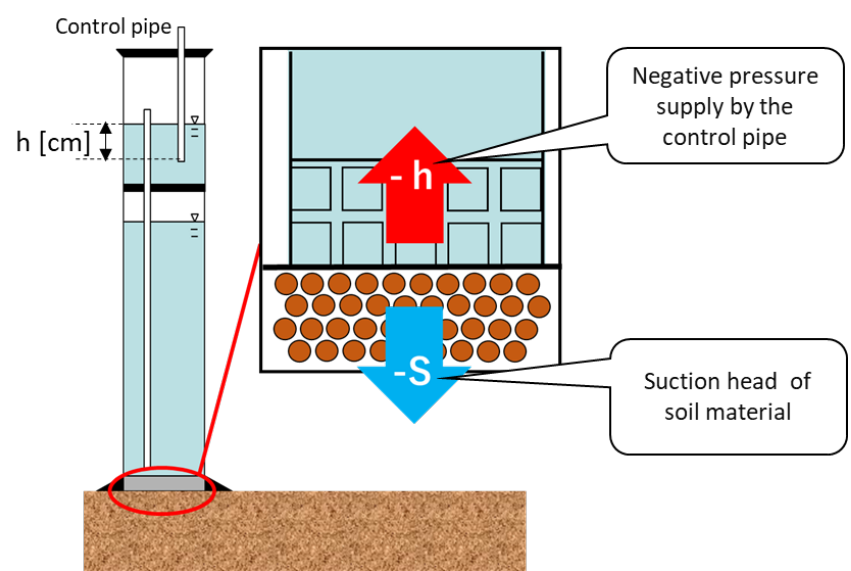

Fig.9 Negative pressure supply and suction head.

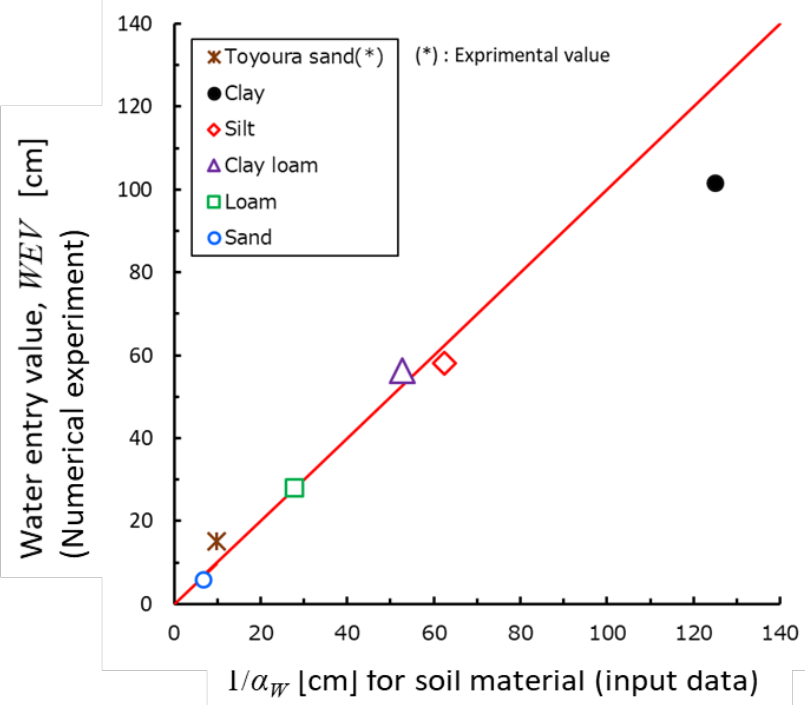

Fig.10 Verification of WEV.

The negative pressure supply and the suction pressure on the pavement (soil) are assumed to be in balance, i.e., the pressure head when the saturated flux is zero, which corresponds to the water entry value (WEV) in Fig. 8.

The WEV indicates the suction head for the soil-water characteristic curve $(S W C C)$ in the wetting process, as shown in Fig. 9, and is equal to the reciprocal of the parameter $\alpha$ in the model of van Genuchten (1986). Therefore, the WEV for the soil-water characteristic curve is considered to be obtainable using the suction infiltration method.

(2) Verification by numerical analysis

Simulation of field-suction infiltration was performed by numerical analysis using four soil materials with known hydraulic properties. The relationship between the numerically determined $W E V$ and the known $W E V(1 / \alpha)$ is shown in Fig. 10. The figure indicates that the negative pressure supply and the suction pressure are in balance, and the $W E V$ can be determined using the suction infiltration method.

\subsection{Determination of soil-water characteristic} curve

Although the $W E V$ can be obtained using the suction infiltration method, it is necessary to determine the parameter $\mathrm{n}$ in the van Genuchten model for assessment of the water retentivity. A method for determining $\mathrm{n}$ is to use the van Genuchten model in conjunction with the suction infiltration method, as follows:

$$
S e=\frac{1}{\left\{1+\left(\alpha \cdot h_{p}\right)^{n}\right\}^{1-1 / n}}
$$

Geometrically, parameters $\alpha$ and $n$ of van Genuchten model are independent of each other. However, from following reason, it seems that there is some relation to those affected by soil particle size and pore size. The smaller soil particle size is, the higher air entry value $(A E V)$ with capillary height is. Therefore, parameter $\alpha_{D}$ of $S W C C$ in drying process becomes smaller. On the other hands, as soil particle size decreases, pore size distribution becomes finer, so it can be easily inferred

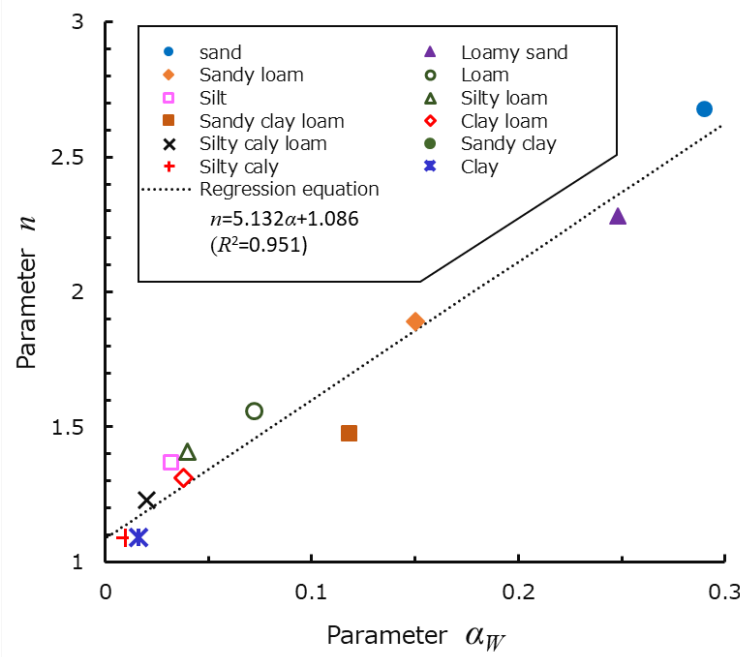

Fig.11.1 Relationship between parameter $\alpha_{W}$ and $n$ (Wetting process).

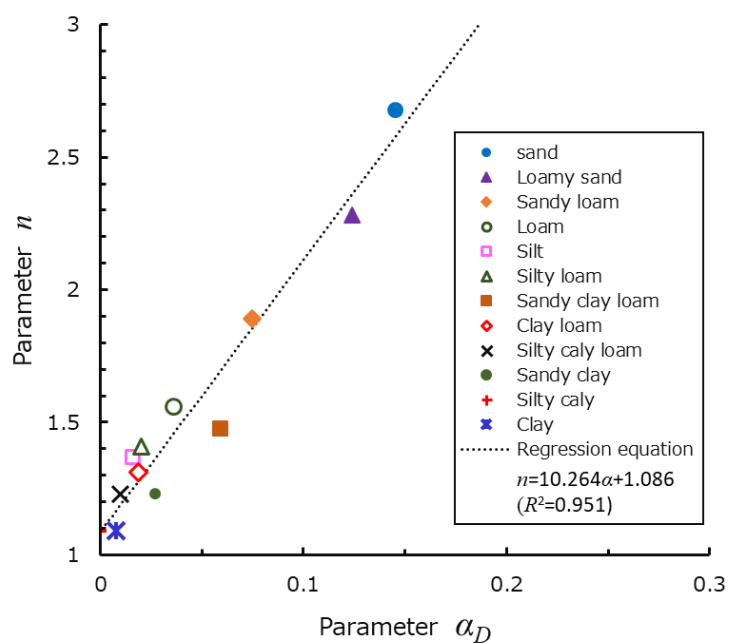

Fig.11.2 Relationship between parameter $\alpha_{D}$ and $n$ (Drying process). 
that $n$ related to gradient $\left(\triangle S e / \Delta h_{p}\right)$ of $S W C C$ becomes smaller. Although this point is clear in some experimental examples, we investigated the relationship between the 12 kinds of soil property data using Hydrus-2D database.

Figure 11.1 shows relationship between $\alpha_{\mathrm{w}}$ and $n$ of $S W C C$ in wetting process. For reference, a relationship between $\alpha_{\mathrm{w}}$ and $n$ of $S W C C$ in drying process as shown in Fig.11.2. Regression equations are following:

- Wetting process

$$
n=5.132 \cdot \alpha+1.086
$$

- Drying process

$$
n=10.264 \cdot \alpha+1.086
$$

However, $n$ in the wetting process and drying process is common, and $\alpha_{D}=0.5 \alpha_{\mathrm{w}}$. In this present paper, we estimated $n$ from Eq. (7) and $\alpha$ obtained in the suction infiltration test, and it was possible to obtain the parameters as shown in Table 1. Where, $\alpha_{D}$ is calculated as half of $\alpha_{\mathrm{w}}$. Figs. 12.1 and 12.2 show SWCC and the calculated unsaturated hydraulic conductivities using the van Genuchten model and Mualem and van Genuchten equation (Eq. (9)) using the parameters in Table 1.

\begin{tabular}{|c|c|c|c|c|}
\hline Side & \multicolumn{3}{|c|}{$W E V(\mathrm{~cm}) \alpha=\alpha_{\mathrm{w}}(1 / \mathrm{cm}) \alpha_{D}(1 / \mathrm{cm})$} & $n$ \\
\hline Point $\mathrm{C}$ & & & & \\
\hline $\begin{array}{c}\text { Soil-based } \\
\text { pavement }\end{array}$ & 7.68 & 0.130 & 0.0651 & 1.754 \\
\hline Point D & & & & \\
\hline $\begin{array}{c}\text { Soil-based } \\
\text { pavement }\end{array}$ & 9.92 & 0.101 & 0.0504 & 1.603 \\
\hline
\end{tabular}

Table1 Estimated parameters

Where, $m$ is $1-1 / n$.

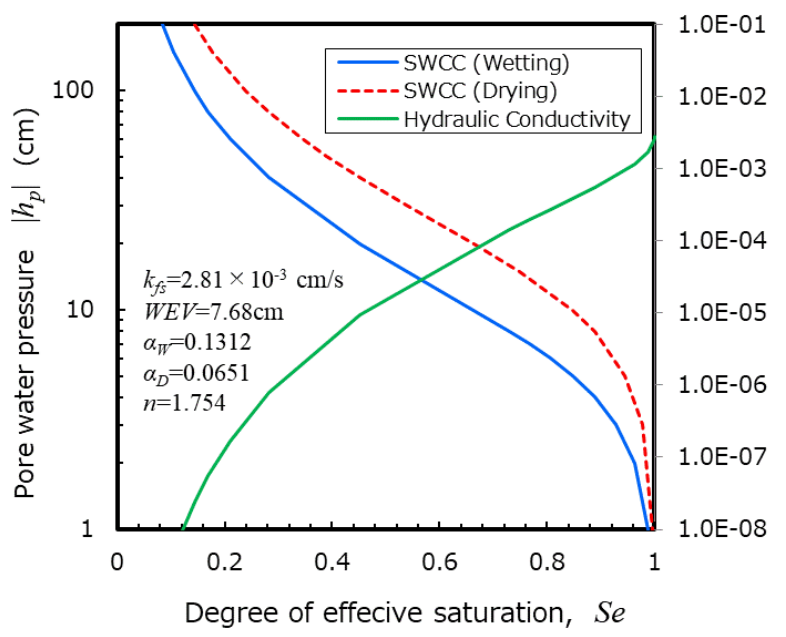

Fig.12.1 Hydraulic properties of unsaturated soils (Point C: Soil-based pavement).

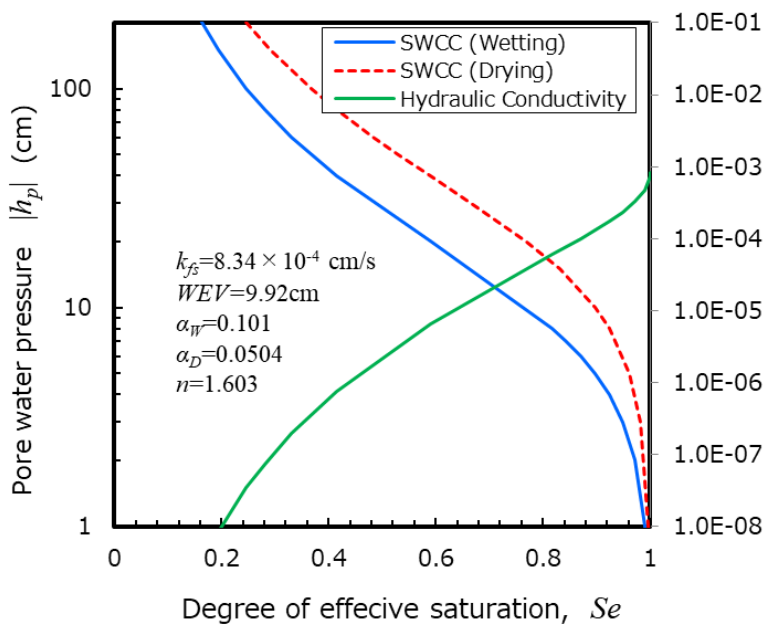

Fig.12.2 Hydraulic properties of unsaturated soils (Point D: Non-pavement).

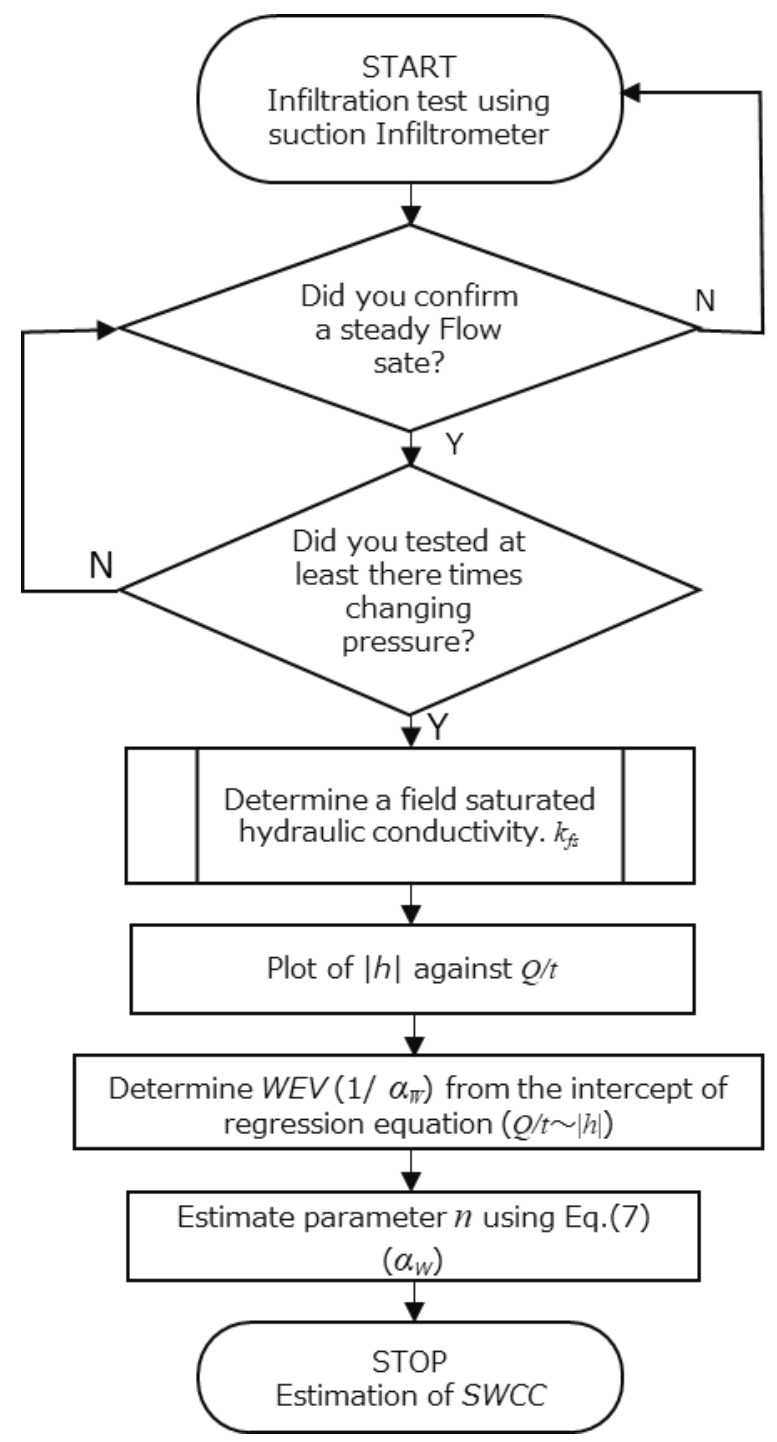

Fig.13 Flowchart for hydraulic properties of unsaturated soils in situ. 
From SWCC, it is judged that Point C (Soil-based pavement) is lower than Point D (Non-pavement) in water retentivity. Since Soil-based pavement is aggregated, the water retention of macro pores in soil-based pavement is evaluated as lower. In order to evaluate the agglomerated soil, it is considered that a multiple phase $S W C C$ approach is required as in Durner's model (Duner (1994)).

A flow chart for obtaining the moisture characteristic curve from the suction infiltration test in situ is shown in Fig.13.

\section{CONCLUSION}

The present study revealed the following:

(1) Even if soil-based pavement with a thickness of up to $10 \mathrm{~cm}$, it can be used to evaluate the field-saturated hydraulic conductivity using the water supply disk with the $22.5 \mathrm{~mm}$ in radius.

(2) The $W E V$ (or parameter $\alpha$ in the $V G$ model) can be determined based on the negative pressure head in balance with the suction head for the pavement after reaching a steady flow.

(3) Geometrically, parameters $\alpha$ and $n$ of van Genuchten model are independent of each other, however, it seems that there is a relationship between $\alpha$ and $n$ due to relate pore structure of particle size.

(4) The hydraulic properties of soil-based pavement in the field can be determined using the suction infiltration method.

\section{ACKNOWLEDGEMENTS}

This work was supported by JSPS KAKENHI Grant Number JP18K04353 and Institute of Science and Technology Research in Chubu University Project II.

\section{REFERENCES}

Sugii,T. and Makino, Y. (2018) : Permeability test at field for a soil type pavement, Chubu Branch of JSCE, III, 263-264 (in Japanese).

Wooding (1968): Steady I filtration from a shallow circular pond, Water Resources Res., 4:1259-1273.

Philip, J. R. (1968): Steady Infiltration from Buried Point Sources and Spherical Cavities, Water Resources Res., 4(5), 1039-1047.

Reynolds, W.D. and D.E. Elrick (1991): Determination of hydraulic conductivity using a tension infiltrometer, Soil Sci. Soc. Am. J.,55: 633-639

Nishimura, T. (2017): An application of tension infiltrometer to evaluate field saturated hydraulic conductivity, DS-1, Proc. of the 52nd Japan National Conference on Geotechnical Engineering (in Japanese).

van Genuhten, M.Th. (1980): A Closed-form Equation for Predicting the hydraulic Conductivity of Unsaturated soils, Soil Sci.Soc. Am.j., Vol.44, 892-898,1980.

Rassam, D., Simunek, J. and van Genuchten Th. (2003): Modelling variably saturated flow with HYDRUS-2D. ND Consult.

Durner, W. (1994): Hydraulic conductivity estimation for soils with heterogeneous pore structure. Water Resour. Res., 30: 211-223. 